\section{PEER-REVIEWED ARTICLE}

Food Protection Trends, Vol 40, No. 5, p. 320-331 Copyright 2020 , International Association for Food Protection 2900 100th Street, Suite 309, Des Moines, IA 50322-3855
Jennifer Pierquet, ${ }^{1}$ Susan W. Arendt, ${ }^{* 2}$ Syafiqah Rahamat, ${ }^{2}$ Nancy Hall, ${ }^{3}$ Steven Mandernach, ${ }^{4}$ Valerie Reeb ${ }^{3}$ and Mark Speltz

${ }^{1}$ lowa Dept. of Inspection and Appeals, 321 East 12 th St. Des Moines, IA 50319, USA

2lowa State University, 2320 Osborn Drive, Ames, IA 50011, USA ${ }^{3}$ State Hygienic Laboratory, University of lowa, Coralville, IA 52241, USA ${ }^{4}$ Association of Food and Drug Officials, 155 West Market St., York, PA 17401, USA

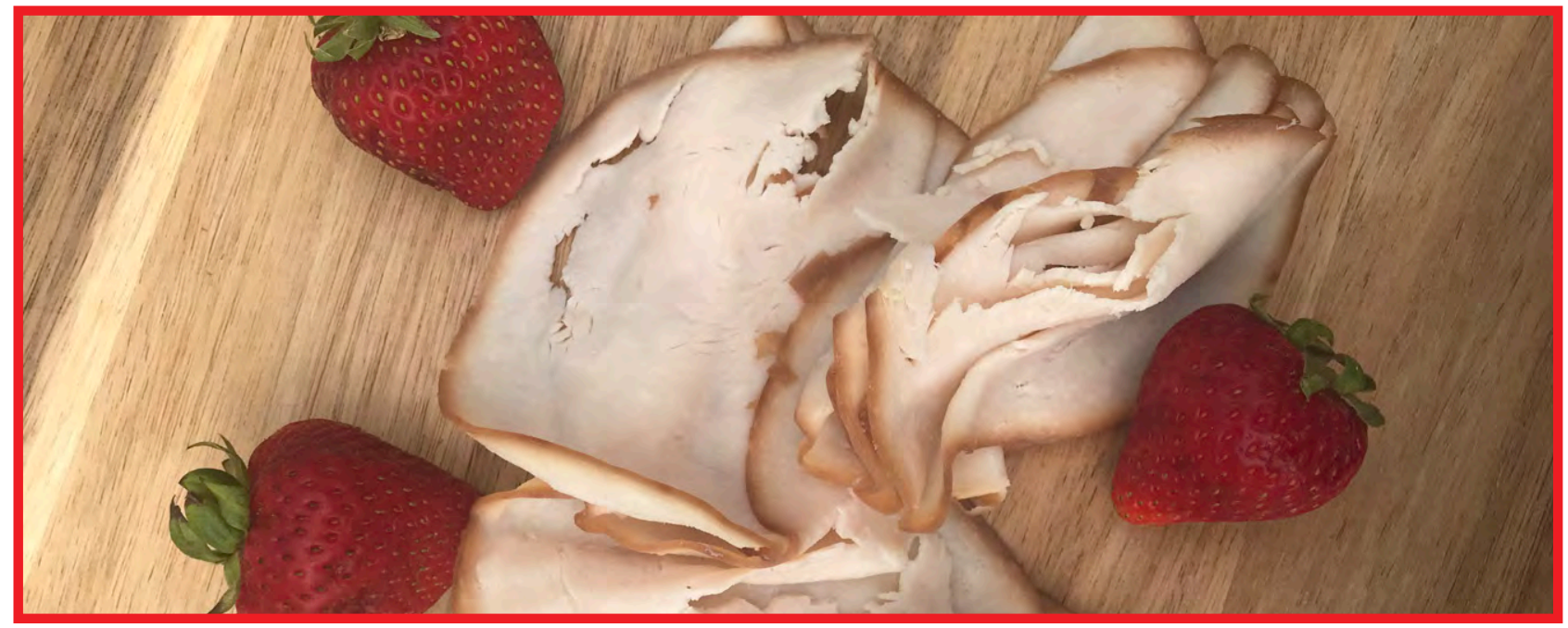

\title{
Listeria monocytogenes Occurrence and Adherence to Recommendations: Small and Large Retail Delicatessens in lowa
}

\section{ABSTRACT}

The goal of this research was to determine the prevalence of Listeria monocytogenes in Iowa retail delicatessens and assess environmental aspects that mitigate L. monocytogenes. Fifty-seven small and large retail delicatessens in Iowa were selected randomly. More small operations $(n=43)$ were included as compared with larger stores, given the higher frequency of violations. An environmental assessment instrument was used to determine environmental factors and practices. At least five microbial samples were collected per site. We collected 286 (74.3\%) of 385 microbial samples from small deli operations and $99(25.7 \%)$ of 385 samples from large deli operations. Samples were taken from various zone 1 and 2 areas, such as the slicer, deli case, and meat scale; three $(0.08 \%)$ samples were positive for L. monocytogenes. Regarding environmental aspects, not preparing, holding or storing ready-to-eat products near raw products $(n=$ $30,53 \%)$ was practiced by the fewest delis. The majority of establishments were observed covering, wrapping, or protecting ready-to-eat products when not in use to prevent contamination ( $n=56,98.2 \%)$. Comparisons were made to the U.S. Department of Agriculture Food Safety and Inspection Service Guidance on environmental practices, and $60 \%$ of the operations surveyed were in adherence with at least seven of the eight recommendations.

Foodborne illness cases are due to various pathogenic bacteria, viruses, and parasites (4). Listeria monocytogenes is one of the main pathogenic bacteria that causes foodborne illnesses. It is widely distributed in environments, such as soil and water (37), and can be found in foods both of animal and plant origins (14). Listeria monocytogenes has ability to persist in biofilms (11) and grow in cold temperatures, including refrigerated storage $(7,50)$. The infection resulting from L. monocytogenes known as listeriosis, is caused when contaminated food is consumed (13). FoodNet data from 2015 indicated 116 cases of listeriosis, with 111 of those resulting in hospitalizations and $15(\sim 13 \%)$ deaths (20). Some individuals are at greater risk for listeriosis, such as those older than 65 years $(26)$ or those who are pregnant $(39,42)$.

Listeriosis outbreaks are often associated with ready-toeat (RTE) foods (51). RTE foods that are at greater risk for causing listeriosis infection are those products that (i) 
have post-lethality exposure to the environment prior to packaging, (ii) are capable of supporting growth of Listeria, and (iii) will not be cooked or treated in any way to eliminate Listeria prior to consumption $(18,23,36)$. Among RTE foods, consumption of contaminated delicatessen meats is one of the main sources of listeriosis and outbreaks (6). In an older study, it was estimated that almost $90 \%$ of human listeriosis cases in the United States were caused by the consumption of contaminated delicatessen meats (45). Endrikat et al. (12) estimated that deadly L. monocytogenes is five times more likely to contaminate delicatessen meats sliced at retail as compared with prepackaged delicatessen sliced meats. In addition, an older study by Gombas et al. (16) found L. monocytogenes was nearly seven times more likely to be found in delicatessen meats prepared in retail establishments. The use of growth inhibitors appears to effect Listeria-associated deaths from both manufactured and retail sliced delicatessen meats (35). A more recent study by Luchansky et al. (28) found that $15(0.25 \%)$ of 5,917 deli meat samples were positive for L. monocytogenes and Listeria-like organisms; chain stores had a slightly higher percentage although not statistically significant. A metaanalysis by Churchill et al. (8) reviewed studies assessing $L$. monocytogenes in deli meats and estimated prevalence to be $2.9 \%$ for those studies with larger samples.

Listeria monocytogenes may enter retail delis through various transmission routes, such as personnel, equipment, raw product, and cross-contamination. The major transmission route results from post-processing contamination that occurs during additional product handling steps, such as slicing (24, $25,35)$. Therefore, given that L. monocytogenes can be present on both food contact and non-food contact surfaces, researchers have conducted sampling of each. Studies conducted by Hoelzer et al. (19) and Sauders et al. (38) in the United States reported 55 to $56 \%$ of retail delis had L. monocytogenes on food contact and non-food contact surfaces. In the study by Sauders et al. (38), 151 (13.0\%) of 1,161 environmental samples tested were confirmed positive for L. monocytogenes, 125 (16.7\%) non-food contact surface and 26 (6.3\%) food contact surface samples. Additionally, one longitudinal study involving 30 retail delis in three U.S. states found $314(6.8 \%)$ samples in the first phase of the study to be confirmed positive for L. monocytogenes and 4,503 (9.5\%) samples in the second phase to be positive (40). Samples were taken from food contact surfaces (e.g., deli case, slicer), non-food contact surfaces (e.g., drain, trash can), and transfer points (e.g., slider knob, scale) in this longitudinal study. Another study conducted at three butcher shops in Brazil, found 87 (60.4\%) samples positive for Listeria spp. and 31 (21.5\%) positive for L. monocytogenes. Samples were taken from various sources, including the hands of employees, tables, knives, grinders, and displays. Tables, grinders, and tenderizers were found to be the main contamination areas for L. monocytogenes presence (10). Regardless of the surface type, an ineffective cleaning program may support the growth and persistence of $L$. monocytogenes for months or years in a deli environment (40).

To explore potential reasons for these positive samples, researchers have studied retail deli environments and employee practices. One such study examined the frequency and adequacy of cleaning retail deli slicers; half of 298 retail delis in the study did not follow the recommended cleaning procedures of the U.S. Food and Drug Administration (FDA) to prevent L. monocytogenes and other pathogenic bacteria. Also, slicers at chain retail delis and in delis with more customers were more adequately cleaned (5) as compared with slicers at delis that were independent or had low customer volume. To mitigate contamination of RTE foods in retail delis, employees must follow safe food handling practices, including maintaining facilities, cleaning and sanitizing equipment, and practicing good personal hygiene. Various policies related to L. monocytogenes in RTE foods have been implemented (2), and the U.S. Department of Agriculture (USDA) Food Safety and Inspection Service (FSIS) has introduced L. monocytogenes guidelines containing eight recommendations (46).

For this study, and in line with previous research findings, the research objectives were as follows: (i) determine the prevalence of $L$. monocytogenes in selected Iowa retail delis and (ii) assess operational environmental aspects that mitigate contamination of RTE products with L. monocytogenes by using eight recommendations in the USDA FSIS $L$. monocytogenes guidelines.

\section{MATERIALS AND METHODS}

Two data collection techniques were used for this study: (i) five to nine microbial samples were collected at each site and (ii) an environmental assessment instrument was used to determine environmental factors and practices. There were two pilot data collection periods and then a final data collection period. Pilot data are not reported.

\section{Pilot study}

For the first pilot, a Listeria self-assessment tool and Hygiena InSite environmental Listeria species test swabs (screening test for Listeria species, Hygiena LLC, Camarillo, CA) were used in nine Iowa retail deli operations. For the Listeria self-assessment tool, inspectors reviewed and recommended changes to questions on the assessment that were confusing; response options were changed from "yes" to "in compliance" and "no" to "out of compliance." In addition, some of the results from the test kits produced false-positive results (culture confirmations performed at the State Hygienic Laboratory, Coralville, Iowa). Therefore, to ensure the accuracy of results, a new test kit was used for the second pilot test.

For the second pilot, a revised version of the Listeria selfassessment and new Hygiena InSite L. monocytogenes Glo (Hygiena LLC) test swabs (screening test for both Listeria species and L. monocytogenes; non-commercial for research 
only) were used to collect data at another nine Iowa retail delicatessen establishments. Similar results to the first pilot occurred with test kits producing false-positive results. On the basis of these results, the decision was made to use traditional sponge stick sampling methodology for the final sampling assignment.

\section{Final collection}

There were 57 small and large retail deli operations in Iowa that were randomly selected for the final data collection. The selection was based on a quota sampling technique with approximately $75 \%(n=43)$ of selected operations being small and the remaining approximately $25 \%(n=14)$ being large operations. Sampling at more small operations was intentional, given the higher frequency of violations in small delis. All data were collected during routine health inspections.

\section{Microbial sample collection}

Three trained individuals visited and collected microbial samples by using a traditional gloved sponge stick technique. Inspectors were trained in aseptic sample collection techniques, which is the standard method for all FDA consumer safety officers during sampling assignments (48). Each sampling required the inspector to collect five to seven samples from clean food contact areas used for RTE delicatessen meat preparation or storage. Sampling site examples were as follows: slicer, meat scale, cutting board, walk-in cooler racks, and deli meat cases. Inspectors labeled each sample bag with the location, sample number, and sample lot number. Information from each sample was captured on a sample collection form with location, sample zone, sample number, and sample lot code. The operator was instructed to reclean any sampled equipment. All samples were shipped the same day in soft-sided coolers to the State Hygienic Laboratory for analysis with the designated chain of custody forms.

\section{Microbiological analyses}

For the final data collection activity, World Bioproducts EZ Reach ${ }^{\mathrm{Tx}}$ sterile polyurethane sponges that contained $10 \mathrm{~mL}$ of Dey-Engley neutralizing broth (EZ-10DE-PUR, World Bioproducts, Bothell, WA) were used for collection and sent to the State Hygienic Laboratory for Listeria species testing and culture confirmation. The microbiological procedures used for the environmental sample processing were from the FDA Bacteriological Analytical Manual (49) and Hygiena BAX System Real-Time PCR Assay for Genus Listeria (D15131113, Hygiena, LLC). Upon receipt in the laboratory, the sponges were homogenized (vigorously hand massaged) with prewarmed University of Vermont media (modified Listeria enrichment broth; Difco, BD, Sparks, MD) broth and incubated at $30^{\circ} \mathrm{C}$ for 20 to $26 \mathrm{~h}$. After primary incubation, $0.1 \mathrm{~mL}$ of primary enrichment was transferred into $10 \mathrm{~mL}$ of morpholinepropanesulfonic acid-buffered Listeria enrichment broth (BD Bacto; BD) with antibiotics $(0.5 \%$ acriflavine, $0.5 \%$ nalidixic acid, and $1 \%$ cycloheximide solutions, Sigma-Aldrich Corporation, St. Louis, MO) and incubated at $35^{\circ} \mathrm{C}$ for 18 to $24 \mathrm{~h}$. Real-Time PCR by using Hygiena BAX System Real-Time PCR Assay for Genus Listeria (D15131113, Hygiena, LLC) was performed first. If the PCR test was positive, aliquots from morpholinepropanesulfonic acid-buffered Listeria enrichment broth were transferred to two agar media: CHROMagar Listeria (CHROMagar, Paris, France) and modified Oxford Listeria selective agar (Difco, BD) containing modified Oxford antimicrobic supplement (Difco, $\mathrm{BD})$. Suspect Listeria colonies were isolated on sheep blood agar plates (Difco, BD) and the Listeria genus and species were confirmed by using matrix-assisted laser desorptionionization time of flight (Daltonics Microflex LT, Bruker Corporation, Boston, MA) mass spectrometry.

All five Listeria monocytogenes isolates recovered for this project were submitted for whole-genome sequencing at the State Hygienic Lab (Table 1). Sequencing material and methods are given in the following.

\section{DNA isolation}

DNA isolation was performed on a QIAcube (Qiagen, Hilden, Germany) instrument by using the QIAamp DNA Mini Kit (catalog \#51306, Qiagen) according to the manufacturer's protocol. Prior to loading bacterial cells on the instrument, an enzymatic digestion was performed by using lysozyme (20 mg/mL; catalog \#L4919, Millipore Sigma, St. Louis, MO) and RNase A (11 ng/ $\mu \mathrm{L}$ final concentration; catalog \#19101, Qiagen). DNA was eluted in $100 \mathrm{~L}$ of 10 $\mathrm{mM}$ Tris $\mathrm{HCl}, \mathrm{pH}$ 8. DNA concentrations were measured on a Qubit 3.0 Fluorometer (Thermo Fisher Scientific Inc., Waltham, MA) by using the Qubit dsDNA BR Assay Kit (catalog \#Q32853, Thermo Fisher Scientific Inc.).

\section{Library preparation and sequencing}

Libraries were prepared by using the Illumina Nextera XT DNA Library Prep Kit (catalog \#FC-131-1096) and Nextera XT Index Kit v2 (catalog \#FC-131-2003, Illumina Inc., San Diego, CA) following the FDA Center for Food Safety and Applied Nutrition protocol "Nextera XT Library Preparation for Sequencing on a MiSeq" (29). Libraries quality were inspected by using the Qubit dsDNA HS Assay Kit (catalog \#Q32854, Thermo Fisher Scientific Inc., Waltham, MA) and the Agilent Bioanalyzer High Sensitivity DNA kit (catalog \#5067-4626, Agilent Technologies Inc., Waldbronn, Germany). Libraries for Listeria were pooled together with other bacterial libraries to reach a total of 160 $\mathrm{Mb}$ per run and sequenced on an Illumina MiSeq instrument (Illumina Inc.) for $2 \times 250$ cycles by using a MiSeq Reagent Kit v3 (catalog \#MS-102-3003, Illumina Inc.). 


\section{TABLE 1. Listeria monocytogenes sequence information from the National Center for Biotechnology Information (NCB)] Pathogen Detection database (50)}

\begin{tabular}{c|c|c|c|c|c|c|c|c}
\hline NCBI biosample & Retailer & Location & $\begin{array}{c}\text { SNP cluster } \\
\text { identification }\end{array}$ & $\begin{array}{c}\text { No. of } \\
\text { isolates } \\
\text { in cluster }\end{array}$ & $\begin{array}{c}\text { SNP range } \\
\text { in cluster }\end{array}$ & $\begin{array}{c}\text { SNP distance } \\
\text { to closest } \\
\text { environmental } \\
\text { isolate }\end{array}$ & $\begin{array}{c}\text { SNP } \\
\text { distance } \\
\text { to closest } \\
\text { clinical } \\
\text { isolate }\end{array}$ & $\begin{array}{c}\text { Collection } \\
\text { date range } \\
\text { within } \\
\text { cluster }\end{array}$ \\
\hline SAMN08437793 & A & $\begin{array}{c}\text { Deli case } \\
\text { girding }\end{array}$ & PDS000025424 & 2 & $1-1(1)$ & 1 & NA $^{a}$ & 2018 \\
\hline SAMN08437795 & B & $\begin{array}{c}\text { Slicer control } \\
\text { meat }\end{array}$ & PDS000025424 & 2 & $1-1(1)$ & 1 & NA & 2018 \\
\hline SAMN08437792 & C & $\begin{array}{c}\text { Deli slicing } \\
\text { table }\end{array}$ & PDS000003255 & 31 & $0-59(14)$ & 1 & 3 & $2014-2018$ \\
\hline SAMN08438037 & D & $\begin{array}{c}\text { Meat } \\
\text { department } \\
\text { floor drain }\end{array}$ & PDS000003204 & 126 & $0-83(35)$ & 11 & 11 & $2013-2019$ \\
\hline SAMN08437794 & D & $\begin{array}{c}\text { Cutting } \\
\text { board on } \\
\text { floor }\end{array}$ & PDS000000366 & 1,109 & $0-108(41)$ & 22 & 20 & $2013-2019$ \\
\hline
\end{tabular}

${ }^{a} \mathrm{NA}$, not applicable.

\section{Sequence data analysis}

Overall run quality was evaluated with the Illumina Sequencing Analysis Viewer v.1.9.1 software (Illumina Inc.) and FastQ files were inspected with FastQC v.0.11.3 (Babraham Institute, Cambridge, UK). Good-quality sequences were shared with the FDA GenomeTrakr Network via BaseSpace (Illumina Inc.). Raw sequence data were submitted to the National Center for Biotechnology Information (U.S. National Library of Medicine, Bethesda, MD) Pathogen Detection database (50) (see Table 1 for biosample numbers). Data were automatically analyzed through the Pathogen Detection pipeline, which includes single nucleotides polymorphism (SNP) comparisons to find clusters of closely related isolates. Isolates were placed in clusters by single-linkage clustering, with a maximum 50 SNPs distance. SNP clusters to which this study's isolates belong can be visualized on the Pathogen Detection Web page (Table 1) (50). To obtain an overview of relationship between the five isolates, analysis was also performed by using a reference-free whole-genome sequencing bioinformatics pipeline (30) (Utah Public Health Laboratory, Salt Lake City, UT) as implemented on the Google Virtual Machine at the Colorado Department of Public Health and Environment (Denver, CO).

\section{Environmental assessment}

For insight into retail deli practices and environmental data, a Listeria self-assessment form was developed and pilot tested twice, prior to use. The assessment form was a modified version of the Listeria monocytogenes deli self- assessment tool (46). All inspectors collecting data used the assessment tool; however, each was first trained on how to use it. In addition, "mark-up" instructions were provided to assure consistency in completion. One example illustrating the detail and clarity of these instructions is as follows:

Item: RTE meat or poultry products refrigerated promptly after use. Mark-up instructions: This item must be marked YES or NO based on direct observations. The item must be marked YES when the regulatory authority determines that RTE products are promptly returned to refrigerated units after slicing. This item may be marked NOT OBSERVED when the establishment is not working with RTE products. Promptly refrigerated after use means: a food product is not left unattended when the food employee changes task unless the task only creates a brief interruption before returning to the product such as serving a retail customer.

Data analysis was conducted by using SPSS (version 23, IBM Corporation, Armonk, NY) software. Descriptive statistics (mean and standard deviation) were calculated. For comparison purposes, the federal retail deli data set related to adherence of eight recommendations was obtained from the presentation "Listeria Controls at Retail: Nationwide Surveillance Results" (17). To compare differences between delis on the basis of size and location, retail delis were divided into two groups: small retail delis and large retail delis. Small delis were defined as those with less than 10 stores in the brand, and large were those with 10 or more stores in the brand. Frequency statistics and $t$-tests were 
TABLE 2. Deli characteristics, samples, and Listeria monocytogenes results

\begin{tabular}{|c|c|c|}
\hline Characteristic & $n$ (of 385 samples) & $(\%)$ \\
\hline \multicolumn{3}{|l|}{ Deli size } \\
\hline Small & 286 & 74.3 \\
\hline Large & 99 & 25.7 \\
\hline Total & 385 & 100.0 \\
\hline \multicolumn{3}{|l|}{ Sample location } \\
\hline Cutting board/prep table & 45 & 11.7 \\
\hline Deli case & 67 & 17.4 \\
\hline Magnetic board & 19 & 4.9 \\
\hline Meat scale & 50 & 13.0 \\
\hline Reach in cooler & 14 & 3.6 \\
\hline Slicer & 139 & 36.1 \\
\hline Walk-in cooler & 43 & 11.2 \\
\hline Knife hilt & 5 & 1.3 \\
\hline Rolling carts or racks & 3 & 0.8 \\
\hline Total & 385 & 100.0 \\
\hline \multicolumn{3}{|c|}{ Confirmed Listeria monocytogenes results } \\
\hline Negative & 382 & 99.2 \\
\hline Positive & 3 & 0.8 \\
\hline Total & 385 & 100.0 \\
\hline
\end{tabular}

performed to compare the percentage of adherence of each eight recommendations between small and large retail delis. Analysis was also done on the basis of location of the delis: rural versus urban. Rural areas were defined as having a population less than 50,000, and urban areas were defined as having a population of 50,000 people or more (44). Frequency statistics and $t$-tests were performed to compare the percentage of adherence to each of the eight recommendations between retail delis located in rural and urban areas.

\section{RESULTS}

\section{Microbial results}

In the final data collection activity, a total of 385 microbial samples were collected in selected Iowa retail deli operations (Table 2). We collected 286 (74.3\%) of 385 microbial samples in small deli operations, and 99 (25.7\%) of 385 samples were collected in large deli operations. These samples were taken from food contact surfaces or surfaces adjacent to food contact surfaces (zones 1 or 2 ) in the operations, including slicer $(n=139,36.1 \%)$, deli case $(n=67,17.4 \%)$, and meat scale $(n=50,13.0 \%)$. Of the total microbial samples $(\mathrm{n}=385)$, only three $(0.8 \%)$ samples were positive for $L$. monocytogenes and one sample was positive for $L$. welshimeri. Of these three positive L. monocytogenes samples (Table 3), one sample was located within a large operation (meat slicer control) and two samples in two different small operations (interior surface of the deli case samples and meat slicer table).

A corrective action sampling assignment was conducted at all small retail delis that had a confirmed positive for Listeria monocytogenes or Listeria species. Listeria species detection is often used by the food industry as an indication that conditions may exist for the presence and growth of L. monocytogenes (31). In addition, the regulatory agency performed corrective action samples because smaller operations may not have the resources to conduct a full environmental sampling of the deli area. The regulatory agency collected between 30 and 40 samples at three operations that were previously sampled during the final sample assignment. The sample collection was conducted with a complete sample team of three inspectors (scribe, sampler, and helper). Another difference between this corrective action sampling and the final sampling was the sampling zones. During the final data collection, all samples were predominately collected in zone 1 . The corrective action 


\section{TABLE 3. Listeria monocytogenes sample results and retail deli operation size ${ }^{a}$}

\begin{tabular}{l|c|c|c|c|c} 
Confirmed L. monocytogenes results & \multicolumn{5}{c}{ Retail deli size: } \\
\hline & Small & $\%$ & Large & $\%$ & \\
\hline Negative & 284 & 99.3 & 98 & 99.0 & \\
\hline Positive & 2 & 0.7 & 1 & 1.0 & \\
\hline Total & 286 & 100 & 99 & 100 & 385 \\
\hline
\end{tabular}

${ }^{a}$ The total number of samples was 383.

$\begin{array}{llll}\text { SAMN08437793 } & \text { A } & \text { PDSO00025424 } \\ \text { SAMN08437795 } & \text { B } & \text { PDS000025424 } \\ \text { SAMN08437792 } & \text { C } & \text { PDS000003255 } \\ \text { Treescale: } 0.001 & \text { SAMN08438037 } & \text { D } & \text { PDSO000003204 } \\ \text { SAMN08437794 } & \text { D } & \text { PDSO00000366 }\end{array}$

FIGURE 1. Randomized Axelerated Maximum Likelihood phylogenetic tree generated by the reference-free pipeline (30). Tree scale $=$ substitution per site.

sampling included zones 1,2 , and 3 , and the majority of positive Listeria samples were collected from zone 3. During the corrective action sample event, the three retailers (A through $\mathrm{C}$ ) that had the L. monocytogenes-positive samples from the original sample assignment did not have any positive Listeria species or L. monocytogenes found. On the other hand, the fourth retailer (D) that had L. welshimeri during the final sample event had two different sites positive for L. monocytogenes (meat department floor drain and cutting board on the floor) during the corrective actions samples, as shown in Table 4. In addition, L. welshimeri and Listeria innocua were also found in retailer D samples from the meat department drain and hallway floor, respectively.

\section{Sequence results}

All five Listeria monocytogenes samples from both sampling assignments were sequenced. The phylogenetic tree shows close relationship of two of the five L. monocytogenes sequenced (Fig. 1). This result is confirmed by the placement of the two isolates (SAMN08437793 and SAMN08437795) within the same cluster PDS000025424 in the U.S. National Library of Medicine Pathogen Detection database (as of January 2019) (50). The isolates, collected in two distinct facilities (A and B), differed by only one SNP, indicating a potentially common source of contamination at both locations. Furthermore, there were no other isolates within cluster PDS000025424, showing that this strain is infrequent in the environment.

The three other isolates (SAMN08437792, SAMN08438037, and SAMN08437794), collected in facilities C and D, were each placed in a different cluster (Table 4). This suggests independent sources of contamination for all three isolates, with facility D being contaminated by more than one strain.

Isolate SAMN08437794, collected from a cutting board on floor in facility D, belongs to the large cluster PDS000000366 (1,109 national isolates total). The closest environmental isolate to SAMN08437794 was collected in Canada in 2018 from raw poultry product (22 SNP distance apart), while 20 SNPs differentiated it from the closest clinical isolate (United States 2018). Isolate SAMN08438037 from the meat 


\section{TABLE 4. Listeria culture positive result summary during sampling events by retailer}

\begin{tabular}{|c|c|c|c|c|c|c|}
\hline \multirow{3}{*}{$\begin{array}{l}\text { Retailer } \\
\text { A }\end{array}$} & \multicolumn{3}{|c|}{ Final sampling event: } & \multicolumn{3}{|c|}{ Corrective action sampling event: } \\
\hline & Species results & $\begin{array}{c}\begin{array}{c}\text { Positive result } \\
\text { sample location }\end{array} \\
\end{array}$ & $\begin{array}{c}\text { Sampling } \\
\text { zone }\end{array}$ & Listeria species results & $\begin{array}{c}\text { Positive result } \\
\text { sample location }\end{array}$ & \begin{tabular}{|c} 
Sampling \\
zone
\end{tabular} \\
\hline & L.monocytogenes & Deli case & 2 & None found & None found & $1-3$ \\
\hline B & L.monocytogenes & Slicer & 1 & $\begin{array}{l}\text { No corrective action } \\
\text { necessary; retailer replaced } \\
\text { slicer }\end{array}$ & & \\
\hline $\mathrm{C}$ & L.monocytogenes & Slicer table ${ }^{a}$ & 1 & L. welshimeri & $\begin{array}{l}\text { Mop bucket } \\
\text { wheel }\end{array}$ & 3 \\
\hline $\mathrm{D}$ & L. welshimeri & Knife holder $^{b}$ & 2 & $\begin{array}{l}\text { L. monocytogenes and } \\
\text { L. welshimeri }\end{array}$ & $\begin{array}{l}\text { Meat } \\
\text { department } \\
\text { floor drain }\end{array}$ & 3 \\
\hline $\mathrm{D}$ & & & & L.monocytogenes & $\begin{array}{l}\text { Cutting board } \\
\text { on floor }\end{array}$ & 2 \\
\hline $\mathrm{D}$ & & & & L. innocua & Hallway floor & 3 \\
\hline
\end{tabular}

${ }^{a}$ Slicer table was sampled during corrective action sampling and was negative for Listeria species.

${ }^{b}$ Knife holder was sampled during corrective action sampling and was negative for Listeria species.

department floor drain at retailer $\mathrm{D}$ was included in cluster PDS000003204 (127 isolates total). It was 11 SNPs apart from the closest environmental isolate (food contact surface, Missouri 2017) and the closest clinical isolate (United States 2016). Isolate SAMN08437792 recovered from a deli-slicing table in facility C belonged to cluster PDS000003255 (31 isolates). This isolate's closest relatives (one SNP distance) were environmental isolates collected in Canada and the United States from food, cantaloupe, RTE product and raw meat (2014 to 2018). The closest clinical isolate (three SNP distance) was collected in 2015 in Canada.

\section{Environmental assessment results}

In terms of adhering to eight of the most important recommended actions identified by the USDA FSIS "retail L. monocytogenes guidance" (Table 5), only 12 operations $(21.1 \%)$ were reported adhering to all eight recommendations as compared with FSIS Pilot Project Results (fiscal year 2016 to 2018; $\mathrm{n}=58$ delis in Iowa, $38.0 \%$ ) (46). For the current study, the majority of participating operations in Iowa $(n=34,59.7 \%)$ adhered to at least seven of the eight recommendations. The fourth recommendation, cover, wrap, or otherwise protect all opened RTE meat or poultry products when not in use to prevent cross-contamination (FDA Food Code), had the highest adherence among deli operations $(n=56,98.0 \%)$. On the other hand, the third recommendation, do not prepare, hold, or store RTE meat or poultry products near or directly adjacent to raw products in the deli case, was least likely for the operations to adhere to $(n=30 ; 53.0 \%$; see Table 6).

Additionally, in the comparison of adherence to each of the eight recommendations between the selected delis in Iowa data set and federal data set (Table 6), Iowa had a higher percentage of adherence to the recommendation to promptly cover the RTE products $(n=56,98 \%)$ as compared with the national data set $(n=3,375,87.5 \%)$. On the other hand, the adherence percentage to the remaining seven recommendations were higher for the federal rather than the Iowa data set used in this study.

Of the 57 operations, a breakdown by location and size was as follows: 35 were small and located in rural areas, 8 were small and located in urban areas, 9 were large and located in rural areas, and 5 were large located in urban areas. In terms of adhering to the eight recommendations by retail deli operation size (Table 7), large retail deli operations had 100\% ( $n$ $=14$ ) adherence to two recommendations: eliminate visibly adulterated product $(P=0.011)$ and refrigerate RTE meal or poultry products promptly $(P<0.001)$. However, small deli operation only had $100 \%(n=43)$ adherence for one recommendation; cover, wrap, or otherwise protect all opened RTE $(P<0.001)$. As compared with small delis, large delis had higher adherence for all eight recommendations, except for adhering to covering, wrapping, and protecting all opened $\operatorname{RTE}(n=13,92.9 \%)$. Among the eight recommendations, adherence to the recommendation related to not preparing, 
TABLE 5. Summary number of lowa retail deli operations and adherence of the eight recommendations of the USDA FSIS retail Listeria monocytogenes guidance

\begin{tabular}{c|c|c}
\hline Adherence to eight recommendations & $n^{a}$ & $\%$ \\
\hline 8 of 8 & 12 & 21.1 \\
\hline 7 of 8 & 22 & 38.6 \\
\hline 6 of 8 & 11 & 19.3 \\
\hline 5 of 8 & 8 & 14.0 \\
\hline 4 of 8 & 2 & 3.5 \\
\hline 3 of 8 & 1 & 1.7 \\
\hline 2 of 8 & 1 & 1.7 \\
\hline 1 of 8 & 0 & 0 \\
\hline
\end{tabular}

$a_{n}=$ number of deli operations in compliance; the total number of deli operations studied $(\mathrm{N}=57)$.

\section{TABLE 6. Summary adherence of eight recommendations of the USDA FSIS retail Listeria monocytogenes guidance with lowa compared with national retail deli operations}

\begin{tabular}{|c|c|c|c|c|}
\hline \multirow[t]{2}{*}{ Recommendation } & \multicolumn{2}{|c|}{ Iowa $(n=57)$} & \multicolumn{2}{|c|}{ USDA FSIS $^{a}(n=3,844)$} \\
\hline & n & $\%$ & n & $\%$ \\
\hline Eliminate visibly adulterated product & 53 & 93.0 & 3,844 & 99.7 \\
\hline Refrigerate RTE meat or poultry products promptly & 49 & 86.0 & 3,735 & 96.7 \\
\hline $\begin{array}{l}\text { Do not prepare, hold, or store RTE meat or poultry products } \\
\text { near or directly adjacent to raw products in the deli case }\end{array}$ & 30 & 53.0 & 3,424 & 88.8 \\
\hline Cover, wrap, or otherwise protect all opened RTE food & 56 & 98.0 & 3,375 & 87.5 \\
\hline $\begin{array}{l}\text { Ensure that sanitary conditions (e.g., no flies, rodent droppings, } \\
\text { mold, or dirty surfaces) are present where RTE meat and } \\
\text { poultry products }\end{array}$ & 44 & 77.0 & 3,726 & 96.6 \\
\hline $\begin{array}{l}\text { Clean and sanitize equipment used to process RTE products at } \\
\text { least every } 4 \mathrm{~h}\end{array}$ & 45 & 79.0 & 3,236 & 83.9 \\
\hline $\begin{array}{l}\text { Eliminate facility conditions in the deli area or storage area that } \\
\text { could cause the products to become adulterated }\end{array}$ & 50 & 88.0 & 3,768 & 97.7 \\
\hline $\begin{array}{l}\text { Ensure that deli employees handling RTE products wear } \\
\text { disposable gloves }\end{array}$ & 42 & 73.6 & 3,733 & 96.8 \\
\hline
\end{tabular}

${ }^{a}$ National data source, see (17).

holding, and storing products near or directly adjacent to raw products was the lowest for both small $(n=22,51.2 \%)$ and large $(n=8,57.1 \%)$ deli operations; this is of particular concern, given the potential for cross-contamination.

In the comparison to adherence to each of eight recommendation between delis located in rural and urban areas (Table 7), it was found that all delis located in rural areas
( $n=44,100 \%$ ) adhered to the recommendation to cover, wrap, or otherwise protect all opened RTE foods. However, all delis located in urban areas $(n=13,100 \%)$ adhered to the recommendation to clean and sanitize equipment used to process RTE products at least every $4 \mathrm{~h}$. Both retail delis in the rural $(n=24,54.5 \%)$ and urban $(n=6,46.2 \%)$ areas least adhered to the "do not prepare, hold, or store RTE meat or 
TABLE 7. Summary adherence of eight recommendations of the USDA FSIS retail Listeria monocytogenes guidance by retail deli operation size and location area

\begin{tabular}{|c|c|c|c|c|c|c|c|c|c|c|}
\hline \multirow[t]{4}{*}{ Recommendation } & \multicolumn{5}{|c|}{ Retail deli size: } & \multicolumn{5}{|c|}{ Retail deli location: } \\
\hline & \multirow{2}{*}{\multicolumn{2}{|c|}{$\begin{array}{c}\text { Small } \\
(n=43)\end{array}$}} & \multirow{2}{*}{\multicolumn{2}{|c|}{$\begin{array}{c}\text { Large } \\
(n=14)\end{array}$}} & \multirow{3}{*}{$P$-value } & \multirow{2}{*}{\multicolumn{2}{|c|}{$\begin{array}{c}\text { Rural } \\
(n=44)\end{array}$}} & \multirow{2}{*}{\multicolumn{2}{|c|}{$\begin{array}{c}\text { Urban } \\
(n=13)\end{array}$}} & \multirow{3}{*}{$P$-value } \\
\hline & & & & & & & & & & \\
\hline & $n$ & $\%$ & $n$ & $\%$ & & $n$ & $\%$ & $n$ & $\%$ & \\
\hline Eliminate visibly adulterated product & 39 & 90.7 & 14 & 100.0 & $0.011^{* a}$ & 41 & 93.2 & 12 & 92.3 & 0.833 \\
\hline $\begin{array}{l}\text { Refrigerate RTE meat or poultry products } \\
\text { refrigerated promptly after use }\end{array}$ & 35 & 81.4 & 14 & 100.0 & $<0.001^{*}$ & 37 & 84.1 & 12 & 92.3 & 0.275 \\
\hline $\begin{array}{l}\text { Do not prepare, hold, or store RTE meat } \\
\text { or poultry products near or directly } \\
\text { adjacent to raw products in the deli case }\end{array}$ & 22 & 51.2 & 8 & 57.1 & 0.388 & 24 & 54.5 & 6 & 46.2 & 0.934 \\
\hline $\begin{array}{l}\text { Cover, wrap, or otherwise protect all } \\
\text { opened RTE }\end{array}$ & 43 & 100.0 & 13 & 92.9 & $<0.001^{*}$ & 44 & 100.0 & 12 & 92.3 & $<0.001^{*}$ \\
\hline $\begin{array}{l}\text { Ensure that sanitary conditions (no flies, } \\
\text { rodent droppings, mold, or dirty surfaces) } \\
\text { are present where RTE meat and poultry } \\
\text { products }\end{array}$ & 31 & 72.1 & 13 & 92.9 & $<0.001^{*}$ & 33 & 75 & 11 & 84.6 & 0.118 \\
\hline $\begin{array}{l}\text { Clean and sanitize equipment used to } \\
\text { process RTE products at least every } 4 \mathrm{~h}\end{array}$ & 32 & 74.4 & 13 & 92.9 & $0.006^{*}$ & 32 & 72.7 & 13 & 100.0 & $<0.001^{*}$ \\
\hline $\begin{array}{l}\text { Eliminate facility conditions in the deli } \\
\text { area or storage area that could cause the } \\
\text { products to become adulterated }\end{array}$ & 37 & 86.0 & 13 & 92.9 & 0.164 & 39 & 88.6 & 11 & 84.6 & 0.460 \\
\hline $\begin{array}{l}\text { Ensure that deli employees handling RTE } \\
\text { products wear disposable gloves }\end{array}$ & 29 & 67.4 & 13 & 92.9 & $0.001^{*}$ & 31 & 70.5 & 11 & 84.6 & 0.155 \\
\hline
\end{tabular}

poultry products near or directly adjacent to raw products in the deli case" recommendation, but the difference was not significant.

\section{DISCUSSION}

Recognizing that microbial sampling was limited to zones 1 and 2, the findings of this study revealed that the slicer table and deli case interior were three sample points in retail delis that were positive for L. monocytogenes. Specifically, one of these sample points (deli case interior) was located within a small operation, and one sample point (slicer control) was located within a large chain operation. Other studies also reported that the meat slicers in retail deli operations were the main areas for cross-contamination and the growth of $L$. monocytogenes because slicers have a complex structure that make them hard to clean $(15,21,24,33)$. Also, it is reported that slicers have many components, such as blade guards and slicer handles, which are linked by seams and seals, and due to continued use, these seals can degrade, allowing debris to become trapped in these areas over time, promoting permissible growth conditions for L. monocytogenes $(23,34)$.

Listeria welshimeri was found at one retailer (D) during the final sampling assignment. Orsi and Wiedmann (31) suggested that the finding of other Listeria species that can also grow at refrigerator temperatures (e.g., L. welshimeri) maybe indicative for conditions that would also support the growth of the pathogenic L. monocytogenes. This was indeed the case for this retailer when during the corrective sampling event at this facility: two different sites were found to be positive for L. monocytogenes. In addition, L. welshimeri and L. innocua were also isolated from two other sites. This retailer would not have been aware of the potential public health problem with the discovery of $L$. monocytogenes, if it had not been for this environmental monitoring project. This retailer adhered to six of the eight FDA guidelines; the two out of adherence were preparing, holding, and storing RTE products near raw products and cleaning and sanitizing equipment. 
Cleaning and sanitizing are essential to preventing the spread of bacteria. Listeria monocytogenes can survive on various surfaces, including stainless steel, which is a common food contact and non-food contact surface in retail deli operations a (e.g., slicers, working tables, and carts). Listeria monocytogenes has an ability to persist in biofilms; it is this biofilm that protects the microorganisms (9). Microorganisms that have biofilms are hard to destroy because of their resistance to sanitizers (32). Sanitizer resistance (sanitizer tolerance) is an important survival strategy of these pathogenic microorganisms (e.g., Listeria) $(1,27,41)$. Retail delis generally used quaternary ammonium compounds as sanitizers (43). However, the effectiveness of these sanitizers to eliminate pathogens, such as L. monocytogenes, could be reduced with the presence of organic residue due to improper cleaning or biofilm formation of the microorganism (32). Therefore, it is important to reinforce proper cleaning and sanitizing to prevent the growth of L. monocytogenes within retail deli establishments. With the ability of Listeria to exist in biofilms, it is recommended that the sanitizers used in the retail deli operations be rotated over time, as noted in the USDA FSIS best practices guidance, "rotate sanitizers as needed to provide more effective bacterial control" (46).

This study compared adherence to the USDA eight recommendations between selected participating retail delis in Iowa with federal data specifically for Iowa (17). When assessing compliance solely related to overall compliance with all eight recommendations, findings were different. On the basis of federal data results (17), there were 58 (38\%) retail delis in Iowa adhering to all eight recommendations; however, for the current study, only $12(21.1 \%)$ retail delis in Iowa were found adhering to all eight recommendations. As compared with the national federal data, the assessed Iowa delis had lower compliance with seven of the eight recommendations except the recommendation to cover, wrap, or otherwise protect all opened RTE foods. Although we did not directly study the relationship, one possible explanation for a lower compliance rate may be in the rigor of the methods used for this study. Inspectors received intense training and "mark-up" instructions to make certain that their evaluations were as accurate as possible when completing the assessment. Thus, the Iowa dataset may be more reliable because confirmation of observations was done. In addition, when observation was not possible (e.g., the observer was not in the facility for $4 \mathrm{~h}$ ), deli managers and/or employees were questioned.

With regard to the USDA FSIS eight recommendations, large retail deli operations in Iowa had a higher percentage as compared with small deli operations in Iowa. This finding is similar with previous studies that found both chain and larger establishments' food safety practices had better compliance than those of independent and smaller establishments. Researchers have noted that chain establishments may be more likely to have tested and verified operational procedures, and they may have better resources, equipment, and staffing (3-5). Overall comparison of Iowa delis located in rural areas as compared with more urban areas revealed those in rural areas had lower compliance with four of the eight recommended practices. Further study of differences between locations of deli may be warranted, although size and location may be linked. More investigation is needed to determine the main causes of these differences in safe food handling practices in Iowa. Additionally, given the limitation of sample size and unequal distribution by location and size, further statistical analysis was not done. Therefore, future studies with larger samples could substantiate the trends presented in this study.

This study assessed the presence of Listeria monocytogenes in zones 1 and 2 during hours when delis were open for business. Although the presence of L. monocytogenes in zones 1 and 2 in sampled Iowa retail delis was relatively low, additional sampling in zone 3 may have revealed different findings, as was observed in the corrective action sampling. Because zones 3 and 4 may not be cleaned and sanitized to the same degree as zones 1 and 2, incorporating these zones into sampling procedures for future studies is needed.

Overall, adherence to all best practice guidance was followed by few of the sampled delis, and compliance in Iowa appeared to be lower than that for the nation. However, over half of the Iowa facilities adhered to six or more of the eight recommended practices, which could have been the reason for the low prevalence of L. monocytogenes. Further studies are needed to confirm this observation. Environmental monitoring similar to what is required for RTE food processing establishments may be one strategy for continual enforcement, awareness, and detection of L. monocytogenes in the retail deli environment (47). The FDA recommends that food processors introduce an environmental monitoring program into their operations. Food processors have several other control measures to consider when trying to mitigate the presence of Listeria in their facilities. These control measures, as well as implementing an environmental monitoring program, may be useful to retail deli operators. The FDA guidance provides processors different strategies for environmental monitoring along with sampling considerations and suggestions on written procedures. The guidance also outlines corrective actions that may be taken in the case of positive L. monocytogenes detection. Although the guide is focused on processors, retail delis could gain valuable insight and procedures to control L. monocytogenes in their establishments.

\section{ACKNOWLEDGMENTS}

This work was partially supported by cooperative agreement 5U18FD005612-03 (rapid response teams) from the U.S. Food and Drug Administration (FDA). Its contents are solely the responsibility of the authors and do not necessarily represent the official views of the FDA. 


\section{REFERENCES}

1. Aase, B., G. Sundheim, S. Langsrud, and L. M. Rørvik. 2000. Occurrence of and a possible mechanism for resistance to a quaternary ammonium compound in Listeria monocytogenes. Int. J. Food Microbiol. 62:57-63.

2. Archer, D. L. 2018. The evolution of FDA's policy on Listeria monocytogenes in readyto-eat foods in the United States. Curr. Opin. Food Sci. 20:64-68. https://doi.org/ 10.1016/j.cofs.2018.03.007.

3. Bogard, A. K., C. C. Fuller, V. Radke, C. A Selman, and K. E. Smith. 2013. Ground beef handling and cooking practices in restaurants in eight states. J. Food Prot. 76:2132-2140.

4. Brown, L. G. 2013. EHS-Net restaurant food safety studies: what have we learned? J. Environ. Health 75:44-45.

5. Brown, L. G. 2016. Retail deli slicer cleaning frequency - six selected sites, United States, 2012. Morb. Mortal. Wkly. Rep. 65:306-310. https://doi.org/10.15585/ mmwr.mm6512a2.

6. Centers for Disease Control and Prevention 2018. Foodborne illnesses and germs: what causes food poisoning. Available at: https:// www.cdc.gov/foodsafety/foodborne-germs. html. Accessed 19 July 2019.

7. Chan, Y. C., and M. Wiedmann. 2008 Physiology and genetics of Listeria monocytogenes survival and growth at cold temperatures. Crit. Rev. Food Sci. Nutr 49:237-253.

8. Churchill, K. J., J. M. Sargeant, J. M. Farber, and A. M. O'Connor. 2019. Prevalence of Listeria monocytogenes in select ready-to-eat foods - deli meat, soft cheese, and packaged salad: a systematic review and meta-analysis. J. Food Prot. 82:344-357.

9. Colagiorgi, A., I. Bruini, P. A. Di Cicco, E. Zanardi, S. Ghidini, and A. I. Ilanieri. 2017. Listeria monocytogenes biofilms in the wonderland of food industry. Pathogens 6:41. https://doi.org/10.3390/pathogens6030041.

10. da Silva, D. A. L., M. R. Dias, M. V. C. Cossi, N. P. A. de Castilho, A. C. Camargo, and L. A. Nero. 2016. Hygiene and safety in the meat processing environment from butcher shops: microbiological contamination and Listeria monocytogenes. J. Food Prot. 79:628-634.

11. Doijad, S. P., S. B. Barbuddhe, S. Garg, K. V. Poharkar, D. R. Kalorey, N. V. Kurkure, D. B. Rawool, and C. Trinad. 2015. Biofilmforming abilities of Listeria monocytogenes serotypes isolated from different sources. PLoS One 10:e0137046. https://doi. org/10.1371/journal.pone.0137046.

12. Endrikat, S., D. Gallagher, R. Pouillot, H. H. Quesenberry, D. LaBarre, C. M. Schroeder, and J. Kause. 2010. A comparative risk assessment for Listeria monocytogenes in prepackaged versus retail-sliced deli meat. J. Food Prot. 73:612-619.

13. Farber, J. M., and J. Z. Losos. 1988. Listeria monocytogenes: a foodborne pathogen. CMAJ 138:413-418.
14. Ferreira, V., M. Wiedmann., P. Teixeira, and M. J. Stasiewicz. 2014. Listeria monocytogenes persistence in food-associated environments: epidemiology, strain characteristics, and implications for public health. J. Food Prot. 77:150-170. https://doi.org/10.4315/0362028X.JFP-13-150

15. Gallagher, D., R. Pouillot, K. Hoelzer, J. Tang, S. B. Dennis, and J. R. Kause. 2016. Listeria monocytogenes in retail delicatessens: an interagency risk assessment—risk mitigations. J. Food Prot. 79:1076-1088. https://doi. org/10.4315/0362-028X.JFP-15-336.

16. Gombas, D. E., Y. Chen., R. S. Clavero, and V. N. Scott. 2003. Survey of Listeria monocytogenes in ready-to-eat foods. J. Food Prot. 66:559-569.

17. Hammons, S. R. 2018. Listeria controls at retail: nationwide surveillance results. Available at: https://www.fsis.usda.gov/ wps/wcm/connect/4e2541bd-feb1-4323950f-5bf1e5342033/Clark-IAFP-070918. pdf?MOD=AJPERES. Accessed 19 July 2019.

18. Hammons, S. R., and H. F. Oliver. 2014. Listeria monocytogenes, listeriosis and control strategies: what the retail deli and food safety manager need to know, p. 43-90. In J. Farber, J. Chrichton, and O. Peter Synder, Jr., (ed.), Retail food safety. Springer, NY.

19. Hoelzer, K., H. F. Oliver, L. R. Kohl, J. Hollingsworth, M. T. Wells, and M. Wiedmann. 2012. Structured expert elicitation about Listeria monocytogenes crosscontamination in the environment of retail deli operations in the United States. Risk Anal. 32:1139-1156. https://doi.org/10.111 1/j.1539-6924.2011.01729.

20. Huang, J. Y., O. L. Henao, and P. M. Griffin. 2016. Infection with pathogens transmitted commonly through food and the effect of increasing use of culture-independent diagnostic tests on surveillance-Foodborne Diseases Active Surveillance Network, 10 U.S. sites, 2012-2015. Morb. Mortal. Wkly. Rep. 2016:65:368-371. https://doi.org/ 10.15585/mmwr.mm6514a2.

21. Keskinen, L. A., E. C. D. Todd, and E. T. Ryser. 2008. Impact of bacterial stress and biofilm-forming ability on transfer of surfacedried Listeria monocytogenes during slicing of delicatessen meats. Int. J. Food Microbiol. 127:298-304. https://doi.org/ 10.1016/j. ijfoodmicro.2008.07.021.

22. Lakicevic, B., and I. Nastasijevic. 2017. Listeria monocytogenes in retail establishments: contamination routes and control strategies. Food Rev. Int. 33:247-269. https://doi.org/10.1080/87559129.2016.1 175017.

23. Lianou, A., and J. N. Sofos. 2007. A review of the incidence and transmission of Listeria monocytogenes in ready-to-eat products in retail and food service environments. J. Food Prot. 70:2172-2198.

24. Lin, C. M., K. Takeuchi, L. Zhang, C. B. Dohm, J. D. Meyer, P. A. Hall, and M. P.
Doyle. 2006. Cross-contamination between processing equipment and deli meats by Listeria monocytogenes. J. Food Prot. 69:71-79.

25. Lipcsei, L, L. G. Brown, E. R. Hoover, B. V. Faw, N. Hedeen, B. Matis, D. Nicholas, and D. Ripley. 2018. Retail deli slicer inspection practices: an EHS-Net study. J. Food Prot. 81:799-805. https://doi.org/10.4315/0362028X.JFP-17-407.

26. Little, C. L., S. M. Pires, I. A. Gillespie, K. Grant, and G. L. Nichols. 2010. Attribution of human Listeria monocytogenes infections in England and Wales to ready-to-eat food sources placed on the market: adaptation of the Hald Salmonella source attribution model. Foodborne Pathog. Dis. 7:749-756.

27. Lourenço, A., E. Neves, and L. Brito. 2009. Susceptibility of Listeria monocytogenes from traditional cheese-dairies to in-use sanitizers. Food Control 20:585-589.

28. Luchansky, J. B., Y. Chen, A. Porto-Fett, R. Poullot, B. Shoyer, and S. Dennis. 2017. Survey for Listeria monocytogenes in and on ready-to-eat foods for retail establishments in the United States (2010 through 2013): assessing potential changes in pathogen prevalence and levels in a decade. J. Food Prot. 80:903-921.

29. Nextera XT Library Preparation for Sequencing on a MiSeq. Available at: http://genomelc.jifsan.org/login?back_url=http\%3A\%2F\%2Fgenomelc.jifsan.org\%2Fprojects\%2Fgenome-learning-community\%2Factivity. Accessed 5 July 2019.

30. Oakeson, K. F., J. M. Wagner, A. Rohrwasser, and R. Atkinson-Dunn. 2017. Whole-genome sequencing and bioinformatic analysis of isolates from foodborne illness outbreaks of Campylobacter jejuni and Salmonella enterica. J. Clin. Microbiol. 56:e00161-18.

31. Orsi, R. H., and M. Wiedmann. 2016. Characteristics and distribution of Listeria spp., including Listeria species newly described since 2009. Appl. Microbiol. Biotechnol. 100:5273-5287. https://doi. org/10.1007/s00253-016-7552-2.

32. Pan, Y., F. Breidt, and S. Kathariou. 2006. Resistance of Listeria monocytogenes biofilms to sanitizing agents in a simulated food processing environment. Appl. Environ. Microbiol. 72:7711-7717.

33. Pouillot, R., D. Gallagher, J. Tang, K. Hoelzer, J. Kause, and S. Dennis. 2015. Listeria monocytogenes in retail delicatessens: an interagency risk assessment-model and baseline results. J. Food Prot. 78:134-145. https://doi.org/10.4315/0362-028X.JFP14-235.

34. Powell, D. A., Jacob C. J., and Chapman B. J. 2011. Enhancing food safety culture to reduce rates of foodborne illness. Food Control 22:817-822.

35. Pradhan, A. K., R. Ivanek, Y. T. Gröhn, R. Bukowski, I. Geornaras, J. N. Sofos, and M. Wiedmann. 2010. Quantitative risk assessment of listeriosis-associated deaths 
due to Listeria monocytogenes contamination of deli meats originating from manufacture and retail. J. Food Prot. 73:620-630.

36. Pradhan, A. K., R. Ivanek, Y. T. Gröhn, R. Bukowski, and M. Wiedmann. 2011. Comparison of public health impact of Listeria monocytogenes product-to-product and environment-to-product contamination of del meats at retail. J. Food Prot. 74:1860-1868.

37. Sauders, B. D., M. Z. Durak, E. Fortes, K. Windham, Y. Schukken, A. J. Lembo, Jr., B. Akey, K. K. Nightingale, and M. Wiedmann. 2006. Molecular characterization of Listeria monocytogenes from natural and urban environments. J. Food Prot. 69:93-105.

38. Sauders, B. D., M. D. Sanchez, D. H. Rice, J. Corby, S. Stich, E. D. Fortes, and M. Wiedmann. 2009. Prevalence and molecular diversity of Listeria monocytogenes in retail establishments. J. Food Prot. 72:2337-2349.

39. Silk, B. J., K. A. Date, K. A. Jackson, R. Pouillot, K. G. Holt, L. M. Graves, K. L. Ong, S. Hurd, R. Meyer, R. Marcus, and B. Shiferaw. 2012. Invasive listeriosis in the Foodborne Diseases Active Surveillance Network (FoodNet), 2004-2009: further targeted prevention needed for higher-risk groups. Clin. Infect. Dis. 54:(Suppl.)396-S404.

40. Simmons, C., M. J. Stasiewicz, E. Wright, S. Warchocki, S. Roof, J. R. Kause, N. Bauer, S. Ibrahim, M. Wiedmann, and H. F. Oliver. 2014. Listeria monocytogenes and Listeria spp. contamination patterns in retail delicatessen establishments in three U.S. states. J. Food Prot. 77:1929-1939.
41. Soumet, C., C. Ragimbeau, and P. Maris. 2005. Screening of benzalkonium chloride resistance in Listeria monocytogenes strains isolated during cold smoked fish production. Lett. Appl. Microbiol. 41:291-296.

42. Southwick, F. S., and D. L. Purich. 1996. Intracellular pathogenesis of listeriosis. N. Engl. J. Med. 334:770-776.

43. Tezel, U., and S. G. Pavlostathis. 2015 Quaternary ammonium disinfectants: microbial adaptation, degradation and ecology. Curr. Opin. Biotechnol. 33:296-304.

44. U.S. Department of Agriculture, Economic Research Service. 2010. Iowa-rural definitions: state-level maps. Available at: https://www.ers.usda.gov/ webdocs/ DataFiles $/ 53180 / 25570$ IA.pdf? $v=0$. Accessed 19 July 2019.

45. U.S. Department of Agriculture, Food Safety and Inspection Service. 2003. Quantitative assessment of the relative risk to public health from foodborne Listeria monocytogenes among selected categories of ready-to-eat foods. Available at: https://www.fda.gov/ downloads/food/foodscienceresearch/ ucm197330.pdf. Accessed 19 July 2019.

46. U.S. Department of Agriculture, Food Service Inspection Service. 2015. Best practices guidance for controlling Listeria monocytogenes in retail delicatessens. Available at: https://www.fsis.usda.gov/wps/ portal/fsis/topics/regulatory-compliance/ compliance-guides-index/controlling-lmretail-delicatessens. Accessed 19 July 2019.
47. U.S. Food and Drug Administration. 2017. Control of Listeria monocytogenes in readyto-eat foods: guidance for industry draft guidance. Available at: https://www.fda.gov/ media/102633/download. Accessed 19 July 2019 .

48. U.S. Food and Drug Administration. 2019. Investigators operations manual. Available at: https://www.fda.gov/inspectionscompliance-enforcement-and-criminalinvestigations/inspection-references. Accessed 10 February 2019.

49. U.S. Food and Drug Administration. 1998 (updated 2017). Detection of Listeria monocytogenes in foods and environmental samples, and enumeration of Listeria monocytogenes in foods. Chapter 10. Bacteriological analytical manual. U.S. Food and Drug Administration, Silver Spring, MD. Available at: https://www.fda.gov/food/ laboratory-methods-food/bam-chapter-10 detection-listeria-monocytogenes-foods-andenvironmental-samples-and-enumeration. Accessed 10 February 2018.

50. U.S. National Library of Medicine. 2019. Pathogen Detection database. Available at: https://www.ncbi.nlm.nih.gov/pathogens. Accessed 10 February 2019.

51. Vongkamjan, K., J. Fuangpaiboon, M. P. Turner, and V. Vuddhakul. 2016. Various ready-to-eat products from retail stores linked to occurrence of diverse Listeria monocytogenes and Listeria spp. isolates. J. Food Prot. 79: 239-245. https://doi. org/10.4315/0362-028X.JFP-15-361. 